\title{
Experimental analysis of direct thermal methane cracking
}

\author{
A. Abánades ${ }^{b, *}$, E. Ruiz $^{a}$, E.M. Ferruelo ${ }^{a}$, F. Hernández $^{a}$, A. Cabanillas ${ }^{a, 1}$, \\ J.M. Martínez-Val ${ }^{b}$, J.A. Rubio ${ }^{a, 1}$, C. López ${ }^{a}$, R. Gavela ${ }^{a}$, G. Barrera ${ }^{a}$, C. Rubbia ${ }^{d}$, \\ D. Salmieri ${ }^{d}$, E. Rodilla $^{c}, D$. Gutiérrez ${ }^{c}$ \\ ${ }^{a}$ Centro de Investigaciones Energéticas, Medioambientales y Tecnológicas (CIEMAT), Madrid, Spain \\ ${ }^{\mathrm{b}}$ Universidad Politécnica de Madrid (UPM), Madrid 28006, Spain \\ ${ }^{\mathrm{C}}$ Vacuum Projects, Valencia, Spain \\ ${ }^{\mathrm{d}}$ European Laboratory for Particle Physics (CERN), Geneva, Switzerland
}

\section{Introduction}

In last two centuries, global energy consumption has doubled every 30 years, in round numbers. Looking ahead, things seem to be very similar, mainly because of the activity of many emerging economics, particularly in Asia. Fossil fuels will continue to be the main energy source for half a century, maybe more [1]. Market and reserves limitations can affect this development, but one can remember that oil reserves have been equivalent for 30-year consumption, one year after the other. Anyway, in less than half a century the $\mathrm{CO}_{2}$ atmospheric content can double, with a dramatic impact in the climate, and therefore in our economy and our lives.
Imaginative solution must be given to provide new ways of energy consumption with considerably reduced $\mathrm{CO}_{2}$ emissions. This is where the so-called Hydrogen Economy appears as a potential, very nice solution; not only for refraining and reducing $\mathrm{CO}_{2}$ emissions but for substituting fossil fuels in the very many combustion applications they are serving nowadays.

In the very long term, $\mathrm{H}_{2}$ will have to be produced from water, using Nuclear Fusion and Renewables. However, early phases in deploying $\mathrm{H}_{2}$ Economy will have to be based on the simplest and more direct methods for $\mathrm{H}_{2}$ production. From this viewpoint, hydrocarbons present some favourable features, and they are already being used for that purpose (Water electrolysis is less than $5 \%$ of the total $\mathrm{H}_{2}$ production, 
and it is only justified by very low prices of electricity and the need of very pure $\mathrm{H}_{2}$ ).

From the point of view of Greenhouse enhancement, Steam-Methane-Reforming (SMR) to produce $\mathrm{H}_{2}$ has the main drawback of $\mathrm{CO}_{2}$ production. In the theoretical process, $1 \mathrm{~mol}$ of $\mathrm{H}_{2}$ requires $0.25 \mathrm{~mol}$ of $\mathrm{CH}_{4}$ as SMR feed. The energy required to be consumed in that endothermic reaction can be obtained by burning $0.05 \mathrm{~mol}$ of $\mathrm{CH}_{4}$. In other words, from $1 \mathrm{~mol}$ of available $\mathrm{CH}_{4}, 0.83$ would be steam-reformed into $3.3 \mathrm{~mol}$ of $\mathrm{H}_{2}$ and $0.83 \mathrm{~mol}$ of $\mathrm{CO}_{2}$; and $0.17 \mathrm{~mol}$ of $\mathrm{CH}_{4}$ would be burned, so producing $0.17 \mathrm{~mol}$ of $\mathrm{CO}_{2}$, which means $0.3 \mathrm{~mol}$ of $\mathrm{CO}_{2}$ per mol of $\mathrm{H}_{2}$.

There is the possibility of heating the SMR unit from nuclear heat [2] or solar heat [3], and no $\mathrm{CH}_{4}$ would have to be burned in the facility. In this case, $0.25 \mathrm{~mol}$ of $\mathrm{CO}_{2}$ would be produced per mol of $\mathrm{H}_{2}$.

$\mathrm{CO}_{2}$ capture (separation) is already available in SMR units. Therefore, the main problem would be $\mathrm{CO}_{2}$ confinement (the so-called sequestration). Several confinement methods have been proposed, but experimental confirmation and actual confinement reliability are far from being established. $\mathrm{CO}_{2}$ sequestration in underground repositories would have to be placed in very low populated areas, which would be an additional economic burden to that potential solution. This point has to be taken into account in the assessment of SMR as a process to accelerate the deployment of the Hydrogen Economy in the context of Sustainable Development.

A sound alternative might be based on $\mathrm{CH}_{4}$ decarburation $[4,5]$ (or hydrocarbon decarburation in general, although methane reserves are the largest ones).

The decarburation reaction is

$$
\mathrm{CH}_{4} \rightarrow \mathrm{C}+2 \mathrm{H}_{2}\left(\Delta \mathrm{h}_{0}=74.85 \mathrm{~kJ} / \mathrm{mol}\right)
$$

It is much less endothermic than SMR, but it also produces less energy in $\mathrm{H}_{2}$ form ( $484 \mathrm{~kJ}$ ) but it presents the fundamental advantage of not producing $\mathrm{CO}_{2}$. Carbon atoms are easily stored, and could be used for producing special materials, as carbon fibres. Besides that, they contain a lot of energy (390 kJ/ mol) that could be exploited in the future, if more $\mathrm{CO}_{2}$ could or should be added to the atmosphere, or reliable sequestration techniques are developed.

There are several advantages in hydrocarbon decarburation as a fundamental process for paving the road to the Hydrogen Economy [4-8]. It did not receive too much attention in the first road-maps outlined to guide this development, but it deserves it, because of energy, environmental and safety reasons. If this technology is developed as can be foreseen, there will also be economic advantages, particularly if $\mathrm{CO}_{2}$ emissions are taxed as needed to avoid climatic changes beyond acceptable values for our current life.

It is worth pointing out that methane decarburation (MDC) is more energy effective than SMR. In this one, the theoretical efficiency in $\mathrm{H}_{2}$ production is $83 \%$. In MDC, the efficiency goes to $84.5 \%$, without taking into account the potential energy contained in $\mathrm{C}$. The savings in $\mathrm{CO}_{2}$ emissions and the commercial value for non-energy uses of the produced black carbon would foster their economical viability. Its main drawback is that it still is an emerging technology.
According to the decarburation reaction equilibrium, working temperatures higher than $1500 \mathrm{~K}$ are needed to obtain a complete decomposition, unless it is stimulated by other mechanisms, as the action of a catalyst [9-12] or the extraction of $\mathrm{H}_{2}$ (and the extraction of $\mathrm{C}$, in order to avoid recombination).

The decomposition reaction is the usual way to produce Carbon Black, a substance with a relatively small but expensive market [13]. There are some methods to carry it out [14-20]. As already said, some of them use a catalyst, which reduces the working temperature below $1000 \mathrm{~K}$, but it conveys other problems, particularly catalyst deactivation (because of carbon deposition, mainly). This obliges to regenerate the catalyst, which is energy consuming (and produces $\mathrm{CO}_{2}$ emissions in some processes). Nevertheless, the main drawback of the available methods is that they are not devised for large-scale production, and the Hydrogen Economy will need very large-scale amounts.

For laboratory research and small industrial productions, electric heating seems advisable, because it can be controlled very easily and can be applied to produce any type of temperature profile, if needed. Additionally, some methods use electric-arc discharges to produce the decomposition $[20,21]$. However they do not fit well with the Hydrogen Economy postulates. It is worth noting that Hydrogen and Electricity will be the main energy carriers in a context of Sustainable Development, with very specific applications on each side.

Industrial heating for future commercial MDC processes could come from solar energy, nuclear reactors or combustion. In the solar field, very high sunlight concentration factors (about 3000) are needed to reach temperatures over $1500 \mathrm{~K}$ [3,22-26]. There are already some designs and experimental set-ups that could be useful for long-term generation of $\mathrm{H}_{2}$ [27]. However, if the objective is to pave the road for advancing the Hydrogen industry, we cannot wait until the maturity of ultra-high temperature solar furnaces. It is without question that they must be considered for the full development of a sustainable Hydrogen Economy, mainly based on water as $\mathrm{H}_{2}$ source, but first stages of $\mathrm{H}_{2}$ development should not rely on additional R\&D programs of very emerging ideas.

Moreover, in MDC there is the possibility to use a fraction of the produced $\mathrm{H}_{2}$ to keep the process going on. Hence, after the start-up for heating the chemical reactor up to the required temperature, Hydrogen would be used as fuel, so minimizing to negligible amounts the $\mathrm{CO}_{2}$ produced. The toll paid for that would be the consumption of $15.5 \%$ of the Hydrogen produced, which would be a drawback for the process, but not a dramatic one. Depending on the price of $\mathrm{CO}_{2}$ emissions, and the actual concern about the Greenhouse enhancement, the process could run in a $\mathrm{CO}_{2}$-free basis or with a small amount of $\mathrm{CO}_{2}$ emissions. In summary, MDC seems a key element to pave the road towards the $\mathrm{H}_{2}$ World along a fast and clean track.

\section{Experimental set-up}

The outlined rationale led to the initiation of a research project at CIEMAT with the support of UPM and Vacuum 


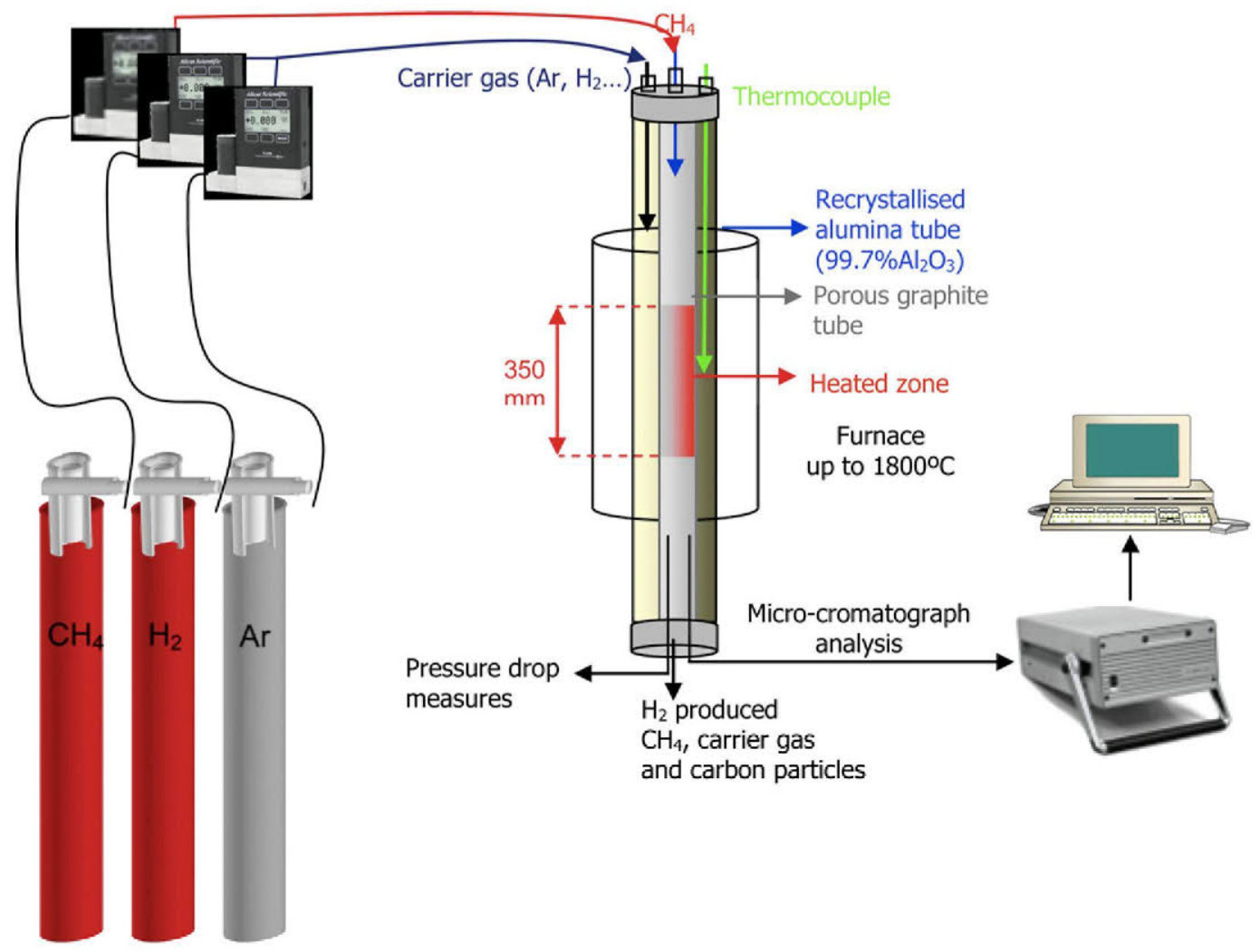

Fig. 1 - Scheme of the experimental set-up for methane cracking research.

Projects and under the supervision of Prof. Carlo Rubbia, 1984 Physics Nobel Laureate and Prof. Juan Antonio Rubio, CIEMAT Director General. The main objective of the project is to demonstrate the scientific and technical viability of methane decarbonisation by thermal cracking to produce free- $\mathrm{CO}_{2}$ Hydrogen.

During the development of the project, two types of furnaces were used to obtain worthy data about the methane decomposition reaction that take place when a technology without catalysts based on direct methane heating is applied, as suggested by many authors $[6,24,27,28]$. The first furnace was able to heat a gas mixture up to $1100^{\circ} \mathrm{C}$. It was our first step towards the determination of the methane conversion to Hydrogen versus temperature, dilution gases as Argon and Hydrogen that are proposed as sweeping gases to avoid Carbon blockage, and residence time.

A second furnace able to reach $1700^{\circ} \mathrm{C}$ was commissioned in a second stage to assess the technical viability of a practical $100 \%$ methane decomposition at high temperature with a negligible dependence of the residence time. Fig. 1 shows an overview of the experimental apparatus, including the test section with the sweeping gas system integrated in a double tube structure with an alumina external tube and porous graphite as internal tube. The sweeping gas (Argon, Helium or Hydrogen) was transferred to the methane stream through the porosity of the internal test tube. Such gas flow was intended to prevent the carbon plug formation. The composition at the outlet of the furnace is obtained by microchromatography.

\section{Experimental results}

Our first experimental results are shown in Fig. 2, in which the amount of Hydrogen at the tube outlet in volume ratio percentage is depicted for three flow rates, which implies three residence times of 16,32 and $96 \mathrm{~s}$ in normal conditions $\left(25^{\circ} \mathrm{C}, 1\right.$ bar) and at a temperature range between 875 and $1065^{\circ} \mathrm{C}$, according to the equation:

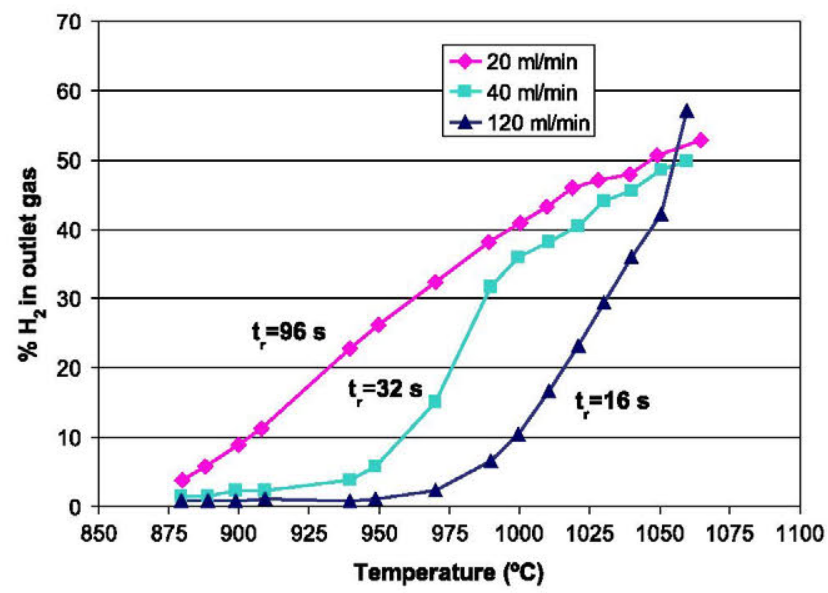

Fig. 2 - Hydrogen volumetric ratio at the outlet gas as a function of the temperature and the flow rate. 


\section{Table 1 - Operating conditions of experimental carried out in the experimental system.}

\begin{tabular}{|c|c|c|c|c|c|c|c|}
\hline Tests No. & $\begin{array}{c}\text { Temperature } \\
\left({ }^{\circ} \mathrm{C}\right)\end{array}$ & Porosity & $\begin{array}{c}\mathrm{CH}_{4} \text { flow } \\
\text { rate }(1 / \mathrm{min})\end{array}$ & & gas & $\begin{array}{l}\text { Residence } \\
\text { time (s) }\end{array}$ & $\begin{array}{c}\text { Methane } \\
\text { conversion (\%) }\end{array}$ \\
\hline Gr-1 & 1350 & Whole tube & 1 & $\mathrm{He}$ & 20 & 0.49 & 74.6 \\
\hline Gr-2 & & & 2 & & & 0.46 & 47.6 \\
\hline $\mathrm{Gr}-3$ & & & 4 & & & 0.42 & 40.2 \\
\hline Gr-4 & 1450 & Whole tube & 1 & $\mathrm{He}$ & 20 & 0.49 & 99.8 \\
\hline Gr-5 & & & 2 & & & 0.46 & 98.0 \\
\hline Gr-6 & & & 4 & & & 0.42 & 99.3 \\
\hline Gr-7 & 1450 & Whole tube & 4 & $\mathrm{He}$ & 80 & 0.12 & 99.8 \\
\hline $\mathrm{Gr}-8$ & & & 8 & & & 0.11 & \\
\hline Gr-9 & 1500 & Whole tube & 8 & $\mathrm{He}$ & 80 & 0.11 & 89.0 \\
\hline Gr-10 & & & 8 & $\mathrm{He}$ & 40 & 0.21 & 92.0 \\
\hline Gr-11 & 1500 (holes) & Holes & 8 & $\mathrm{He}$ & 40 & 0.21 & 94.4 \\
\hline Gr-12 & 1500 & $50 \mathrm{~cm}$ porous zone & 4 & $\mathrm{He}$ & 20 & 1.2 & 93.0 \\
\hline $\mathrm{Gr}-13$ & 1500 & $50 \mathrm{~cm}$ porous zone & 4 & $\mathrm{He}$ & 40 & 0.65 & 99.3 \\
\hline $\mathrm{Gr}-14$ & 1500 & $20 \mathrm{~cm}$ porous zone & 4 & $\mathrm{He}$ & 20 & 1.2 & 94.6 \\
\hline Gr-15 & 1500 & Not porous & 4 & - & - & 7.2 & 99.0 \\
\hline Gr-16 & 1700 & Whole tube & 0.1 & $\mathrm{Ar}$ & 0.5 & 41.7 & 95.5 \\
\hline Gr-17 & & & 0.2 & & & 35.8 & 96.7 \\
\hline Gr-18 & & & 0.3 & & & 31.3 & 97.4 \\
\hline Gr-19 & & & 0.4 & & & 27.8 & 97.7 \\
\hline Gr-20 & & & 0.5 & & & 25 & 98.0 \\
\hline Gr-21 & 1700 & Whole tube & 0.1 & $\mathrm{H}_{2}$ & 0.5 & 41.7 & 95.2 \\
\hline $\mathrm{Gr}-22$ & & & 0.2 & & & 35.8 & 97.4 \\
\hline $\mathrm{Gr}-23$ & & & 0.3 & & & 31.3 & 99.2 \\
\hline $\mathrm{Gr}-24$ & & & 0.4 & & & 27.8 & 99.3 \\
\hline $\mathrm{Gr}-25$ & & & 0.5 & & & 25 & 99.7 \\
\hline
\end{tabular}

$t_{\mathrm{R}}=\frac{l \cdot A}{q}$

where $l$ is the length of the tube, $A$ is cross section and $q$ the volumetric flow rate. The results show how the Hydrogen production rises with temperature, reaching a conversion to Hydrogen of about a $30 \%$, after taking into account the production of 2 mols of Hydrogen per mol of methane. The residence time becomes negligible at higher temperatures as the reaction kinetics is faster.

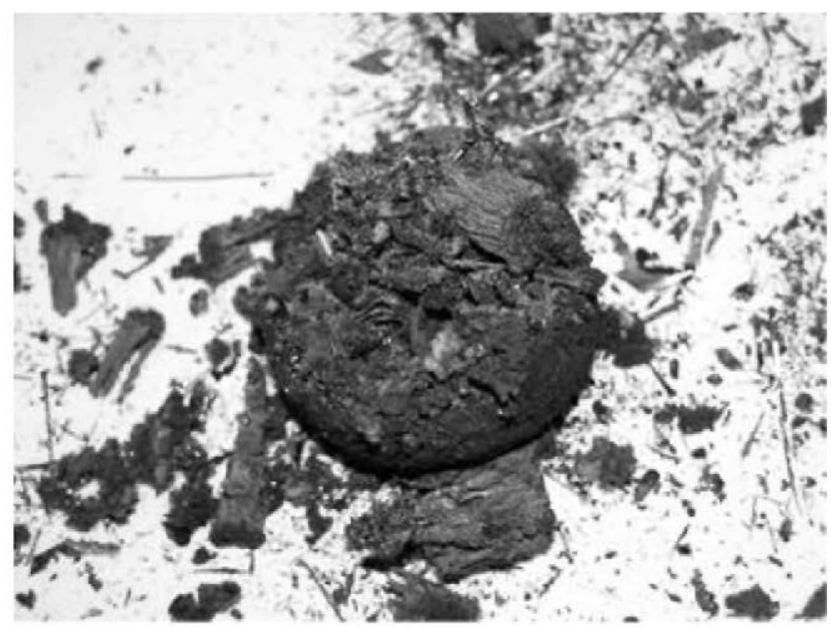

Fig. 3 - Carbon plug specimen obtained at Gr-4 experiment.
After the scientific feasibility has been proven, our experimental work has been focused in the evaluation of different operation conditions depending on:

- Maximum operation temperature.

- Sweeping/carrier gas fraction.

- Methane flow rate.

- Residence time.

- Type of sweeping/carrier gas.

- Tube porosity.

- Tube material.

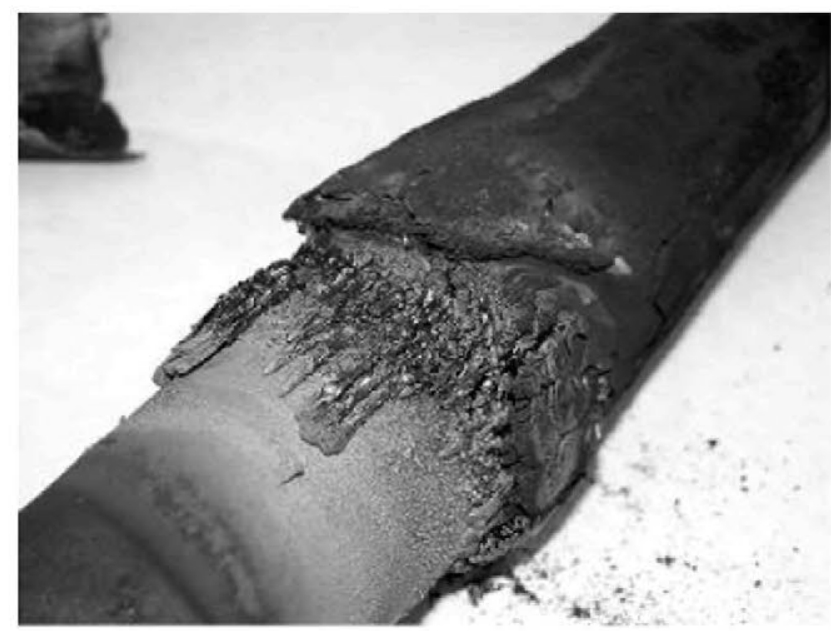

Fig. 4 - Carbon depositions on the external surface of the graphite tube. 


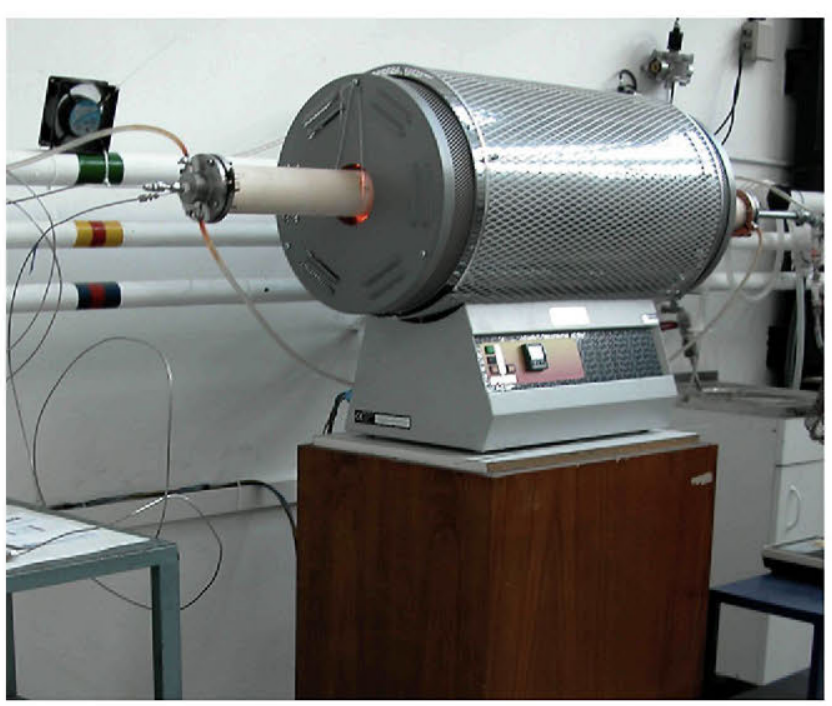

Fig. 5 - Horizontal furnace for SiC experiments.

The operating temperature will be the most important parameter concerning the methane conversion rate and the hydrogen generation rate. High temperatures produce high Methane to Hydrogen conversion rates.

The fraction of additional sweeping gas could be expected to have an influence in the conversion rate through the reaction products-reactants chemical balance and its dilution effect. Nevertheless, at high temperatures with the decarburation reaction far to the right, the reaction balance will be affected slightly, although it is not expected a very important effect in the methane conversion.

The main set of experiments has been done using a graphite tube with different degrees of porosity in order to assess the effectiveness of the sweeping gas to avoid carbon deposition in the tube. Most of the experiments have been done in a porous tube, except Gr-11, that was a tube with a few- $\mu \mathrm{m}$ holes, Gr-12 and Gr-13 with a tube in which the porous zone was limited to $50 \mathrm{~cm}$ around the hottest part, where the reaction was expected to take place, Gr-14 with a $20 \mathrm{~cm}$ porous zone, and $\mathrm{Gr}-15$ with no porosity.

Table 1 shows the summary of the experimental work carried at different temperatures. Above $1450^{\circ} \mathrm{C}$, a conversion close to $100 \%$ is obtained, with a complete reaction for residence times above $0.20 \mathrm{~s}$. At $1350^{\circ} \mathrm{C}$ there is a small dependence on the residence time and type of gas, as well as its dilution. In fact, the highest the conversion of methane into Hydrogen, the lowest the residence time effect, as the reaction kinetics become very fast.

As it can be seen in Table 1, various porous tubes were used to examine whether carbon plug could be avoided or not, and the results showed that they could not effectively prevent the carbon plug formation. In every of these experiments there was a carbon plug phenomena that limited the experiment time last. The plug, shown in Fig. 3, appears after a certain time that can vary from $30 \mathrm{~min}$ to $4 \mathrm{~h}$ depending on the operating temperature and, basically, the amount of Hydrogen formation and methane flow. A higher Hydrogen conversion, implies a higher black carbon production, and consequently, a faster carbon plug growth. Small quantities of Carbon particles are removed by the gas flow at the outlet of the tube.

Consequently, the main show-stopper in this process is the carbon plug formation that finally blocks the gas flowing through the tube reactor and makes very difficult its technological design. The challenge to avoid the formation of the carbon plug was the reason to try different materials and the analysis of the carbon formation, including its aggregation structure and hardness.

The carbon formation in the reacting tube affects its external surface as well, as can be shown in Fig. 4, which implies that carbon particles are able to diffuse through the tube wall, likely due to a low remaining porosity, compatible with the particle size of the order of $\mathrm{nm}$. On the other hand, after the plug formation, heated methane is able to cross through the porosity of the wall and react forming the carbon black layer, in spite of the sweeping gas.

The results with graphite tubes show that carbon deposition becomes an operational problem as carbon trends to aggregate to the tube inner surface at the reaction temperature.

The testing of new materials suggested the use of Silicon Carbide $(\mathrm{SiC})$ as candidate material. Four tests were made to assess if the carbon plug could be avoided with such material.

The tests were done in a horizontal furnace shown in Fig. 5 , except the experiment at $1200^{\circ} \mathrm{C}$ that was done in the high temperature vertical furnace of previous experiments, that was unable to increase temperature due to a malfunction of one of the three electric coils used for heating, which forced the utilisation of the vertical furnace. The effect of the flow direction was negligible.

Table 2 - Summary table of the SiC tube experiments.

\begin{tabular}{|c|c|c|c|c|}
\hline Experiment \# & 1 & 2 & 3 & 4 \\
\hline $\mathrm{T}\left({ }^{\circ} \mathrm{C}\right)$ & 1200 & 1300 & 1400 & 1400 \\
\hline Tube & $\mathrm{SiC}$ & $\mathrm{SiC}$ & $\mathrm{SiC}$ & $\mathrm{SiC}+$ Boron Nitrate layer \\
\hline $\mathrm{CH}_{4}$ flow $(1 / \mathrm{min})$ & 1 & 1.1 & 1 & 1 \\
\hline Ar flow $(1 / \mathrm{min})$ & 1 & 0.9 & 1 & - \\
\hline Time (h) & 3 & 3 & 3 & 3 \\
\hline Dissociation rate & $\begin{array}{l}10 \% \text { methane in exit. } \\
\text { Hydrocarbons presence. }\end{array}$ & $\begin{array}{l}3 \% \text { methane in exit. } \\
\mathrm{H}_{2} \text { presence } 60-70 \% \text {. }\end{array}$ & $\begin{array}{l}0 \% \text { methane in exit } \\
\text { (complete dissociation) }\end{array}$ & $\begin{array}{l}0 \% \text { methane in exit } \\
\text { (complete dissociation) }\end{array}$ \\
\hline & Unknown $\mathrm{H}_{2}$ production. & Very Low hydrocarbons presence. & $\mathrm{H}_{2}$ presence $93-94 \%$ & $\mathrm{H}_{2}$ presence $93-94 \%$ \\
\hline \multirow{2}{*}{ Carbon deposit } & Soft carbon black & Soft dust carbon black & Soft dust carbon black & Soft dust carbon black \\
\hline & & $\begin{array}{l}\text { Carbon black } \\
\text { Hard carbon black }\end{array}$ & $\begin{array}{l}\text { Carbon black } \\
\text { Hard carbon black }\end{array}$ & Hard carbon black \\
\hline
\end{tabular}




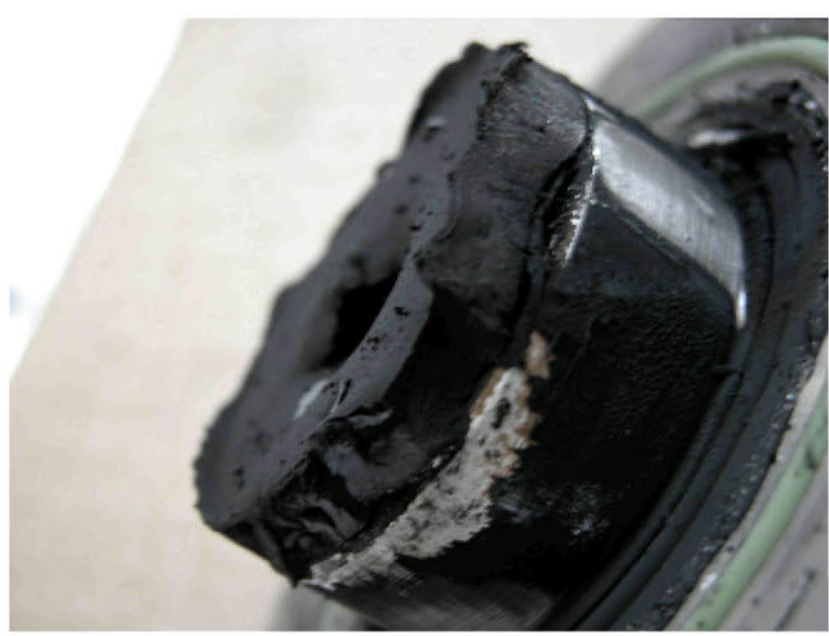

Fig. 6 - Soft carbon plug at $1200^{\circ} \mathrm{C}$.

The experimental campaign made analysis of the carbon plug formation and reaction efficiency in an operational temperature range from 1200 to $1400^{\circ} \mathrm{C}$, with Argon as sweeping gas. The main results for the $\mathrm{SiC}$ tubes are shown in Table 2. The results are comparable with previous tests in graphite tubes regarding temperature influence in the methane to hydrogen conversion ratios, which proves the negligible effect due to the tube material change.

At $1200^{\circ} \mathrm{C}$ there is formation of soft carbon deposition along the tube and at the outlet (Fig. 6) that can be easily removed. A very hard carbon deposition appears in the hottest part of the tube wall when temperature is above $1300^{\circ} \mathrm{C}$. Air oxidation can regenerate the $\mathrm{SiC}$ tube but produce $\mathrm{CO}_{2}$.

A test at $1400^{\circ} \mathrm{C}$, with an external layer of Carbon Nitrate to eliminate the porosity of the tube, was also done. The performance of the experiment was similar to the previous one, which implies a negligible effect of the porosity with $\mathrm{SiC}$ tubes.

\section{Analysis of the carbon deposition}

The main show-stopper for a technological application of this process is the formation of a carbon deposit in the tube wall. Such deposit starts with a carbon particle generation, whose formation has its better thermal conditions at the tube wall, that get adhered to tube, acting as a seed for a growing hard carbon structure.

In this section, a review of the available information about the carbon particles produced at different temperatures is shown.

An analysis of the characteristics of the carbon deposition has been done in function of the process temperature by the characterization of the black carbon deposition at every test performed with different tubes. In a first approximation, it is expected that the characteristics of the carbon formed do not depend on the tube material, but mainly on the temperature and the reaction kinetics that could affect the final size of the carbon particles. The first set of data has been obtained by the experiments that were done with a quartz tube, from 1000 to $1100^{\circ} \mathrm{C}$. A second set of data resume the information available up to $1700^{\circ} \mathrm{C}$, obtained with graphite and $\mathrm{SiC}$ tubes.

The size of the carbon particles could be related to the aggregation structure and its hardness, as well as it could be an important factor in relation with the pore size in the tube. In fact, the observed formation of carbon deposits in the outer surface of the tube is produced by the migration through the pores of particles, or methane molecules. Such problems should be solved by non-porous tubes.

Fig. 7a) shows the amorphous black carbon powder in the plug at $1000^{\circ} \mathrm{C}$. Fig. 7b) shows the electron microscopy analysis of the carbon deposit in the surface of the quartz tube, formed by a silver grey, brittle film adhered to the quartz surface. It can be seen as the carbon aggregation has a smooth structure, with a characteristic length of the carbon black in a range from 1 to $5 \mu \mathrm{m}$.
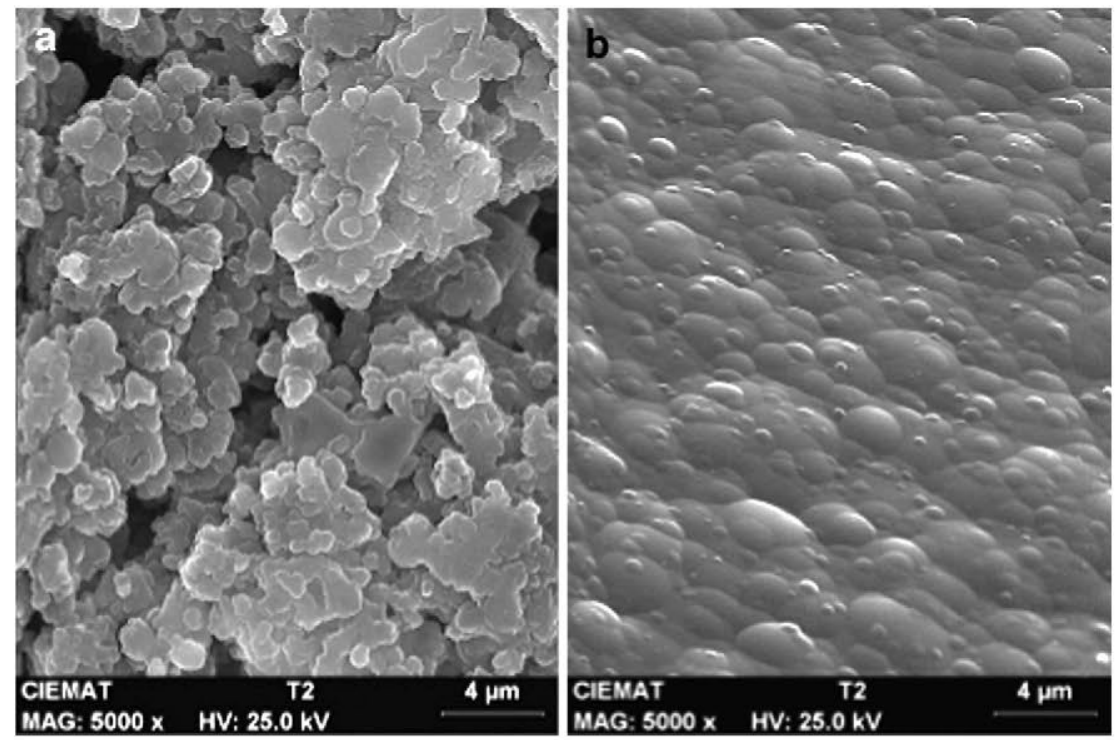

Fig. 7 - Carbon formed at $1000^{\circ} \mathrm{C}$ and $60 \mathrm{ml} / \mathrm{min}$. a) In the plug, b) in the tube. 

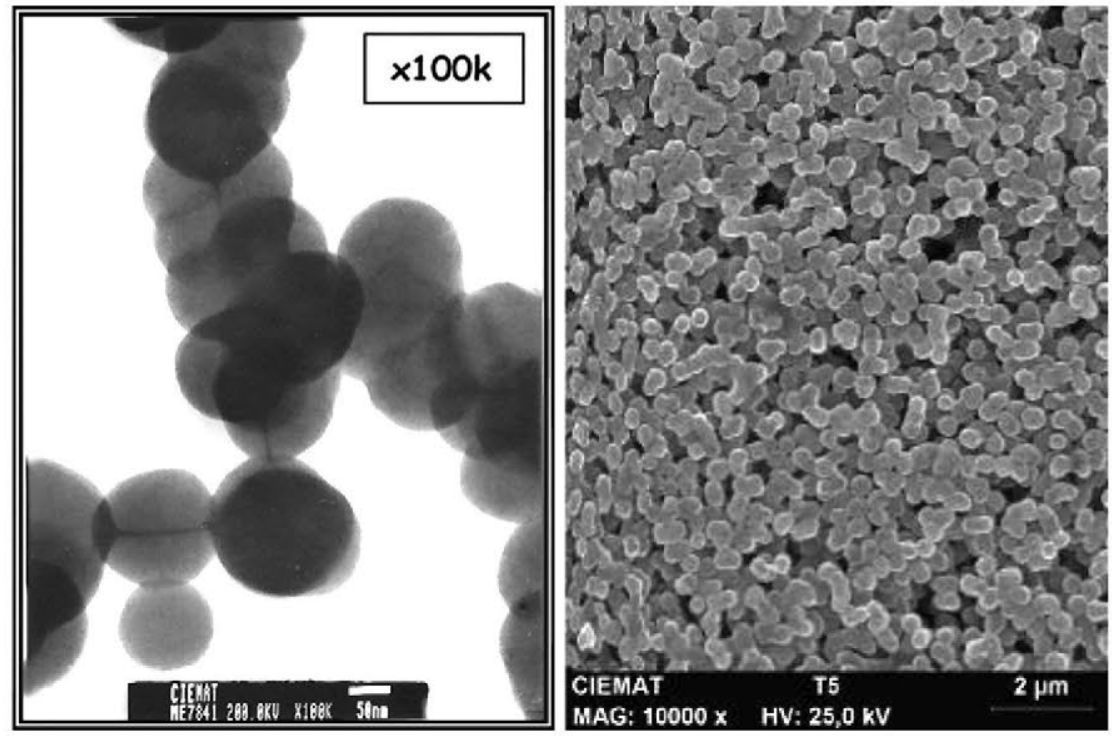

Fig. 8 - Carbon formed at $1100^{\circ} \mathrm{C}$ without sweeping gas.

Fig. 8 shows the carbon formation in the centre of the tube at this temperature without sweeping gas. The tendency shows that the size of the aggregation particles is on average from 150 to $300 \mathrm{~nm}$, with an amorphous morphology and a low crystallization level, as it was obtained from X-ray diffraction analysis.

In Fig. 9, we can see the black carbon particles at $1100^{\circ} \mathrm{C}$ using Argon as sweeping gas with different gas/methane feeding ratios. The average size of the particles formed was between 10 and $0.5 \mu \mathrm{m}$. Using Argon, the average particle size was between 1 and $0.4 \mu \mathrm{m}$, the higher the dilution ratio, the higher the particle size. This fact can be explained as the increase in the dilution ratio reduces slightly the reaction kinetics and a lower amount of initiating carbon seed is produced. Below $1100^{\circ} \mathrm{C}$, the Hydrogen generation and the carbon formation are very low, with high residence times.
The carbon particles in the central part of the experimental tube at $1450^{\circ} \mathrm{C}$ were analysed and the particle size was between 100 and $300 \mathrm{~nm}$. The conversion rate was almost $100 \%$, using Helium as carrier gas. When the Hydrogen formation is efficient appear carbon particles below $500 \mathrm{~nm}$ size that form a hard plug in the tube wall.

Electron spectroscopy of the carbon formed at $1500^{\circ} \mathrm{C}$ shows a smooth graphitic structure, as it is shown in Fig. 10. Several tests have been done at this temperature with Helium as carrier gas, and different tube configuration regarding the porous section of the tube. The results show how that sweeping gas system is not effective to eliminate the carbon formation shown in Fig. 4, with a clear diffusion of methane or carbon particles through the pores of the tube, producing the harmful deposit in the outer surface, and producing the tube blocking as well.
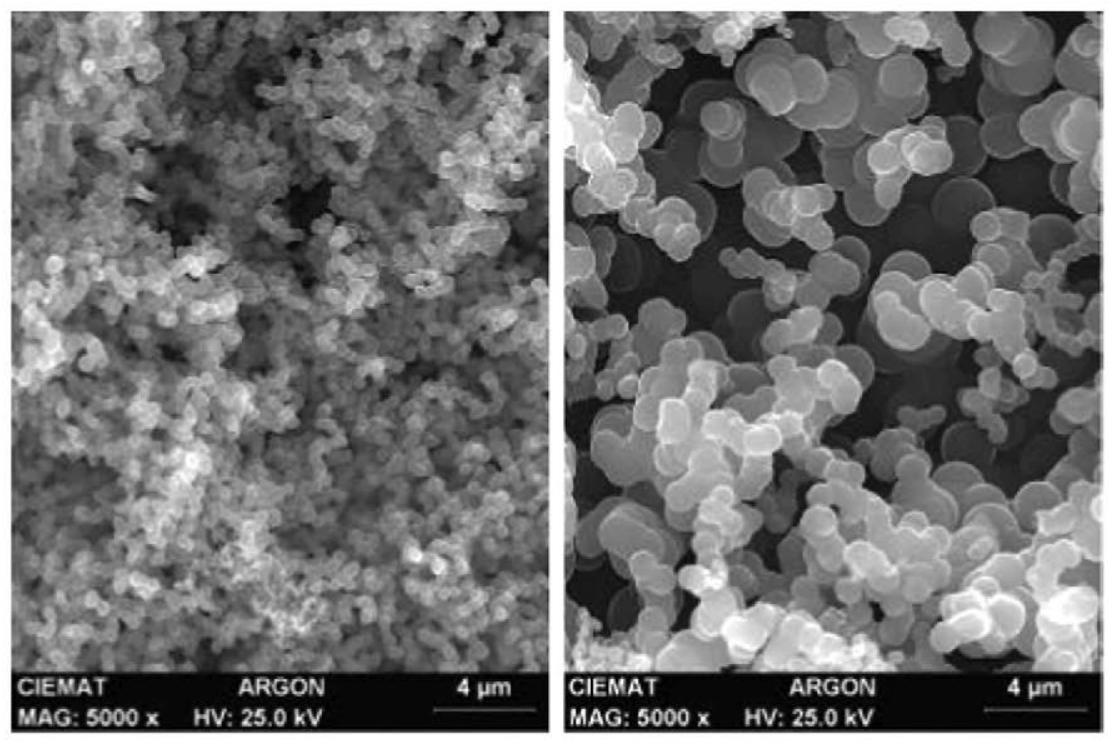

Fig. 9 - Carbon formed at $1100{ }^{\circ} \mathrm{C}$ with Argon sweeping gas with gas/ $\mathrm{CH}_{4}$ ratio from 1 to 5 . 

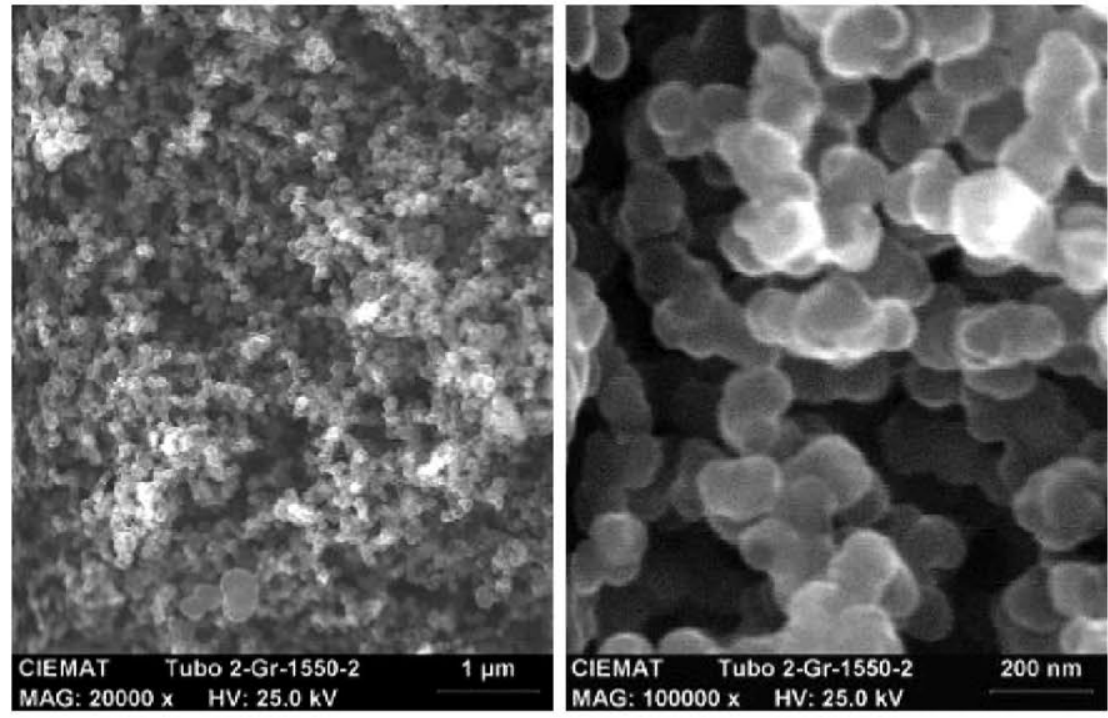

Fig. 10 - Electron microscopy of the carbon produced at $1500^{\circ} \mathrm{C}$ with different augmentation.

Fig. 11 shows the cross section of the graphite tube with the carbon plug after 35 min test with a porous tube. Fig. 12 shows the carbon deposition at the outer surface of the tube after the $3 \mathrm{~h}$ test that was achieved with a theoretically non-porous tube, which suggests there is practical black carbon diffusion at high temperature through the tube.

At this temperature, it was proven that the sweeping gas system in a tubular reactor seems inefficient for a long-term operation, at least under reasonable pressures and at temperatures with high conversion ratio.

Fig. 13 shows the electroscopy analysis of the carbon formation that was obtained at $1700^{\circ} \mathrm{C}$, with particle sizes of the order of micrometres, which is two orders of magnitude respect to the previous experiments. Such carbon formations are very hard and a mechanical extraction is very risky for the structural integrity of the tube, at least at cold conditions. On the other hand, most of the carbon produced in the methane conversion reaction is fixed to the tube according to our estimation.

The conclusion from the carbon analysis is that at the optimal temperatures for the chemical processes $\left(>1400^{\circ} \mathrm{C}\right)$ there is a formation of carbon particles of the order of some $100 \mathrm{~nm}$, that form a hard carbon structure deposition in the tube wall that finally leads to the tube blockage. A summary of the particles size is shown in Table 3 .

The use of ceramic tubes, with a certain porosity, produces the diffusion of methane, through the pores, producing a formation of the deposit at the outer surface of the tube, when the carbon plug begins its formation. It is likely that such formation increases pressure losses in the tube and some methane flows through the porous tube.

There is no evidence of a relation between the size of the particles and the carbon aggregation hardness, which depends mainly on the temperature.

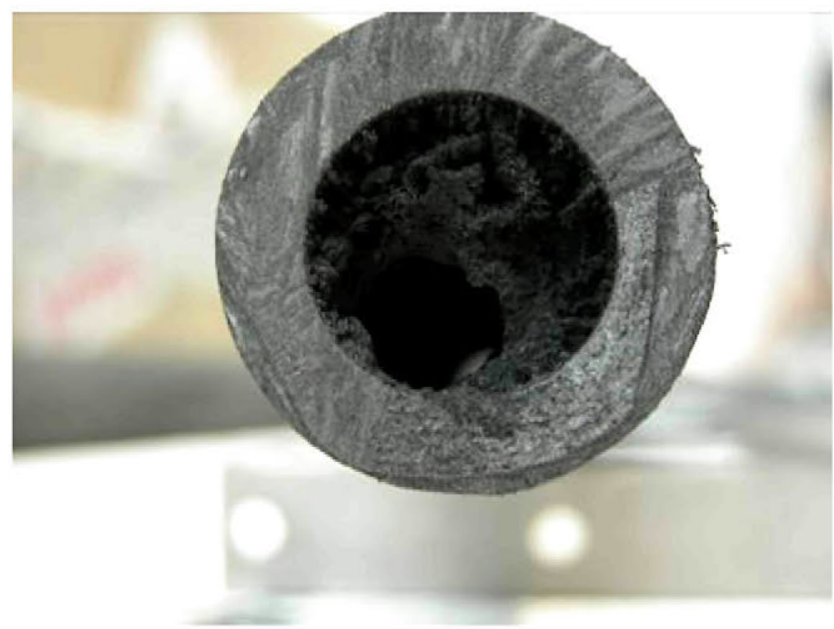

Fig. 11 - Cross section of the graphite tube after $35 \mathrm{~min}$ of test.

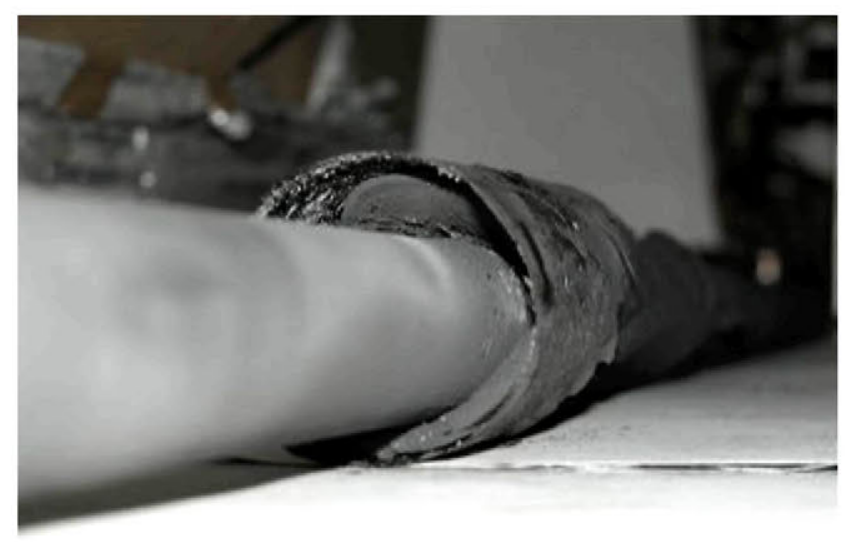

Fig. 12 - Graphite tube after $3 \mathrm{~h}$ tests for the experiment Gr-15, with a non-porous tube. 


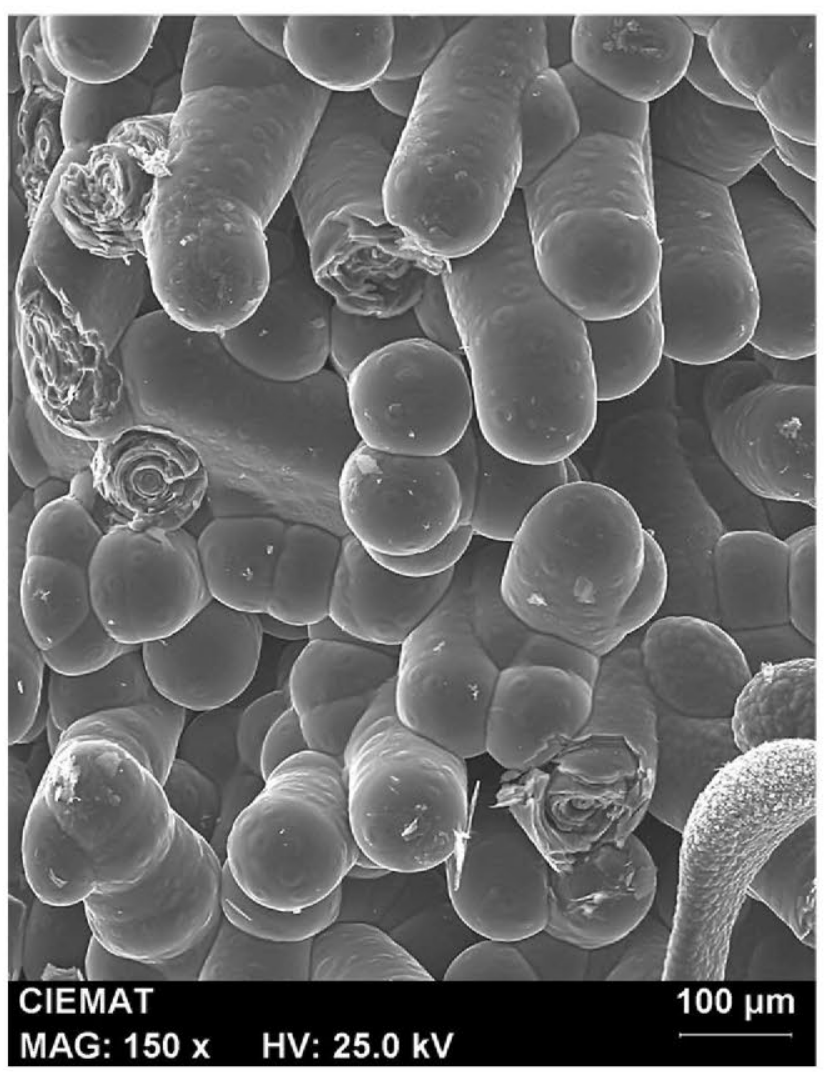

Fig. 13 - Carbon particles formed during the tests at $1700^{\circ} \mathrm{C}$.

Table 3 - Summary of carbon particle size versus temperature.

\begin{tabular}{lc} 
Temperature $\left({ }^{\circ} \mathrm{C}\right)$ & Carbon black size at tube \\
\hline 1000 & $1-5 \mu \mathrm{m}$ \\
1065 & $500 \mathrm{~nm}$ \\
1450 & $100-300 \mathrm{~nm}$ \\
1500 & $90-500 \mathrm{~nm}$ \\
1700 & $50 \mu \mathrm{m}$ \\
\hline
\end{tabular}

\section{Conclusion}

Experimental results on methane thermolysis inside a tube reactor seem to confirm that there are two reacting regimes depending on the reactor temperature. Such reaction regimes are slightly influenced by residence time, and by the dilution effect of the sweeping gas. In general, those effects are almost negligible.

1. At a furnace temperature lower than $1200^{\circ} \mathrm{C}$, methane decomposition is not complete, and many hydrocarbons and other reaction intermediate products appear in the outgoing stream, with a sizeable fraction of $\mathrm{H}_{2}$ and a visible cloud of carbon powder. In the case of our SiC tube test, carbon deposition is produced but easily removable by its weak agglomeration. Nevertheless, previous tests with
Quartz tubes show how during long operation tests, carbon deposition in the reactor wall could produce blockage. The low efficiency on the methane to hydrogen conversion implies that the amount of carbon produced is finally lower and the growing deposit has worst conditions for their development.

2. At temperatures higher than $1350^{\circ} \mathrm{C}$, the decomposition is practically complete, and the main component of the outgoing gas is $\mathrm{H}_{2}$, with almost no traces of hydrocarbon gases. A cloud of carbon powder still goes out, but a huge fraction of the produced carbon appears as solid deposits firmly stick to the wall. Elimination of the deposit by simple mechanical pushing is very difficult, at least in cold conditions. That carbon deposit can be eliminated by combustion, just by blowing air into the hot oven, so producing $\mathrm{CO}_{2}$, which is undesirable.

It is not simple to characterize the composition of the outgoing gas in the first regime, but it seems there are mixtures of hydrocarbons and free radicals produced as intermediate steps in the reaction, and in equilibrium at the temperatures reached in the experiments. Carbon particles seem to accompany those molecules, without sticking to the wall material.

On the contrary, in the second regime the thermolysis is complete, and very hot carbon aggregates stick to the wall in a similar way to a crystal growing process. The deposit grows continuously if the test lasts for long, so producing a total blocking of the inner tube, and stopping the flow of gas. At this operating regime, as carbon deposition blocks the tube, methane is forced to cross the porous wall and produces also carbon deposition in the outer surface.

The tube material has had a negligible effect in our experiments. Quartz, graphite and SiC tubes present similar results respect to residence time, Hydrogen generation and carbon plug formation.

\section{REFERENCES}

[1] Moriarty P, Honnery D. Hydrogen's role in an uncertain energy future. Int J Hydrogen Energy 2009;34:31-9.

[2] Hori M, Spitalnik J. Nuclear production of hydrogen. American Nuclear Society; 2004. ANS-690064.

[3] Bilgen E, Galindo J. High temperature solar reactors for hydrogen production. Int J Hydrogen Energy 1981;6: $139-52$.

[4] Abbas HF, Wan Daud WMA. Hydrogen production by methane decomposition: a review. Int J Hydrogen Energy 2010;35:1160-90.

[5] Steinberg M. Fossil fuel decarbonization technology for mitigating global warming. Int J Hydrogen Energy 1999;24: 771-7.

[6] Hirsch D, Epstein M, Steinfeld A. The solar thermal decarbonization of natural gas. Int J Hydrogen Energy 2001; 26:1023-33.

[7] Serban M, Lewis MA, Marshall CL, Doctor RD. Hydrogen production by direct contact pyrolysis of natural gas. Energy Fuel 2003;17:705-15.

[8] Lane J, Spath P. Technoeconomic analysis of the thermocatalytic decomposition of natural gas; 2001. NREL/TP 510-31351. 
[9] Shah N, Panjala D, Huffman GP. Hydrogen production by catalytic decomposition of methane. Energy Fuel 2001;15: 1528-34.

[10] Takenaka S, Shigeta Y, Tanabe E, Otsuka K. Methane decomposition into hydrogen and carbon nanofibers over supported $\mathrm{Pd}-\mathrm{Ni}$ catalysts: characterization of the catalysts during the reaction. J Phys Chem B 2004;108(23):7656-64.

[11] Ju Y, Li F, Wei R. Methane decomposition into carbon fibers over coprecipitated nickel-based catalysts. J Nat Gas Chem 2005;14:101-6.

[12] Suelves I, Lazaro MJ, Moliner R, Corbella BM, Palacios JM. Hydrocarbon production by thermocatalytic decomposition of methane on Ni-based catalysts. Int J Hydrogen Energy 2005;30:1555-67.

[13] Donet JG. Carbon black. New York: Marcel Dekker Pub.; 1976.

[14] Funk JE. Thermochemical hydrogen production: past and present. Int J Hydrogen Energy 2001;26:185-90.

[15] Muradov NZ. How to produce hydrogen from fossil-fuels without $\mathrm{CO}_{2}$ emission. Int J Hydrogen Energy 1993;18:211-5.

[16] Poirier MG. Catalytic decomposition of natural gas to hydrogen for fuel cell applications. Int J Hydrogen Energy 1997;22:429-33.

[17] LiX, etal. Methane conversion to $C_{2}$ hydrocarbons and hydrogen in atmospheric non-thermal plasmas generated by different electric discharge techniques. Catal Today 2004;98:617-24.

[18] Hydrogen production methods. MPR Associates Inc., http:// www.mpr.com/pubs/hydroprod.pdf; 2005.

[19] Muradov NZ. $\mathrm{CO}_{2}$ free production of hydrogen by catalytic pyrolysis of hydrocarbon fuel. Energy Fuel 1998;12:41-8.
[20] Yang Y. Direct non-oxidative methane conversion by nonthermal plasma: experimental study. Plasma Chem Plasma Process 2003;23(2):283-96.

[21] He J, Hu M, Lu Z. Methane decomposition and $\mathrm{C}_{2}$ hydrocarbon formation under the condition of DC discharge plasma. J Nat Gas Chem 2004;13:244-7.

[22] Steinfeld A, Kirillov V, Kuvshinov G, Mogilnykh Y, Reller A. Production of filamentous carbon and hydrogen by solar thermal catalytic cracking of methane. Chem Eng Sci 1997; 5280:3599-603.

[23] Dahl JK, Tamburini J, Weimer AW. Solar thermal processing of methane to produce hydrogen and syngas. Energy Fuel 2001;15:1227-32.

[24] Dahl JK, Buecher KJ, Weimer AW, Lewandowski A, Bingham C. Solar-thermal dissociation of methane in a fluid-wall aerosol flow reactor. Int J Hydrogen Energy 2004; 29:725-36.

[25] Steinfeld A. Solar thermochemical production of hydrogen a review. Sol Energy 2005;78:603-15.

[26] Trommer D, Hirsch D, Steinfeld A. Kinetic investigation of the thermal decomposition of $\mathrm{CH}_{4}$ by direct irradiation of a vortex-flow laden with carbon particles. Int J Hydrogen Energy 2004;29:627-33.

[27] Abánades S, Flamant G. Solar hydrogen production from the thermal splitting of methane in a high temperature solar chemical reactor. Sol Energy 2006;80:1321-32.

[28] Kogan M, Kogan A. Production of hydrogen and carbon by solar thermal methane splitting. I. The unseeded reactor. Int J Hydrogen Energy 2003;28:1187-98. 